\title{
Serum Biomarkers for Prediction of Response to Methotrexate Monotherapy in Early Rheumatoid Arthritis: Results from the SWEFOT Trial
}

\author{
Karen Hambardzumyan, Rebecca J. Bolce, Johan K. Wallman (D), Ronald F. van Vollenhoven (iD, \\ and Saedis Saevarsdottir (D)
}

ABSTRACT. Objective. To investigate baseline levels of 12 serum biomarkers that constitute a multibiomarker disease activity test, as predictors of response to methotrexate (MTX) in patients with early rheumatoid arthritis (eRA).

Methods. In 298 patients from the Swedish Pharmacotherapy (SWEFOT) clinical trial, baseline serum levels of 12 proteins were analyzed for association with disease activity based on the 28 -joint count Disease Activity Score (DAS28) after 3 months of MTX monotherapy using uni-/multivariate logistic regression. Primary outcome was low disease activity (LDA; DAS28 $\leq 3.2$ ).

Results. Of 298 patients, 104 achieved LDA after 3 months on MTX. Four of the 12 biomarkers [C-reactive protein (CRP), leptin, tumor necrosis factor receptor I (TNF-RI), and vascular cell adhesion molecule 1 (VCAM-1)] significantly predicted LDA based on stepwise logistic regression analysis. Dichotomization of patients using receiver-operating characteristic curve analysis-based cutoffs for these biomarkers showed significantly higher proportions with LDA among patients with lower versus higher levels of CRP or leptin ( $40 \%$ vs $23 \%, p=0.004$, and $40 \%$ vs $25 \%, p=0.011$, respectively), as well as among those with higher versus lower levels of TNF-RI or VCAM-1 (43\% vs 27\%, p = 0.004, and $41 \%$ vs $25 \%, p=0.004$, respectively). Combined score based on these biomarkers, adjusted for known predictors of LDA (smoking, sex, and age), associated with decreased chance of LDA (adjusted OR $0.45,95 \%$ CI $0.32-0.62$ ).

Conclusion. Low baseline levels of CRP and leptin, and high baseline levels of TNF-RI and VCAM-1 were associated with LDA after 3 months of MTX therapy in patients with eRA. Combination of these 4 biomarkers increased accuracy of prediction. [Trial registration number: NCT00764725] (First Release February 1 2019; J Rheumatol 2019;46:555-63; doi:10.3899/jrheum.180537)

Key Indexing Terms: RHEUMATOID ARTHRITIS BIOMARKERS

METHOTREXATE PREDICTION RESPONSE

\begin{abstract}
From the Rheumatology Unit, Department of Medicine, Karolinska Institutet and Karolinska University Hospital, Stockholm, Sweden; Crescendo Bioscience, South San Francisco, California, USA; Section of Rheumatology, Department of Clinical Sciences Lund, Lund University, Lund, Sweden; Amsterdam Rheumatology and Immunology Center, Amsterdam, the Netherlands; Institute of Environmental Medicine (IMM), Karolinska Institutet, Stockholm, Sweden.

This work was supported in part by a grant from the Swedish Rheumatism Association. Some of the authors were supported by clinical research funds from Stockholm County (ALF funds). An annual unrestricted grant was provided by Schering-Plough Sweden, which was used to support a study coordinator and a medical monitor for the original clinical trial. $R J B$ received consultancy fees from Crescendo Bioscience.

K. Hambardzumyan, MSc, Rheumatology Unit, Department of Medicine Solna, Karolinska Institutet and Karolinska University Hospital;

R.J. Bolce, MSN, Crescendo Bioscience; J.K. Wallman, MD, PhD, Section of Rheumatology, Department of Clinical Sciences Lund, Lund University; R.F. van Vollenhoven, $M D, P h D$, Rheumatology Unit, Department of Medicine Solna, Karolinska Institutet and Karolinska University Hospital, and Amsterdam Rheumatology and Immunology Center; S. Saevarsdottir, MD, PhD, Rheumatology Unit, Department of Medicine Solna, Karolinska Institutet, and Unit of Translational Epidemiology, Institute of Environmental Medicine, Karolinska Institutet.
\end{abstract}

Address correspondence to Dr. S. Saevarsdottir, Unit of Translational Epidemiology, Institute of Environmental Medicine, Karolinska Institutet,

\author{
Nobels väg 13, SE-17165, Solna, Stockholm, Sweden. \\ E-mail: saedis.saevarsdottir@ki.se \\ Accepted for publication October 9, 2018.
}

Methotrexate (MTX) is recommended as the first-line treatment of early rheumatoid arthritis (eRA) ${ }^{1,2}$. However, about $60-70 \%$ of patients do not achieve low disease activity ${ }^{3}$ [MTX-incomplete responders (MTX-IR)] and need further intensification of their treatment. Identification of patients who would or would not benefit from MTX monotherapy could contribute to a personalized approach and optimal therapy choice at baseline.

Several factors have been shown to be associated with higher or lower effectiveness of MTX therapy. For example, male sex and nonsmoking status were predictive of response ${ }^{4-16}$. Other identified predictors are short symptom duration before diagnosis and lower disease activity at

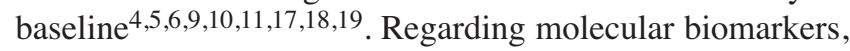
Maillefert, et al demonstrated in 42 patients with RA (of whom 19 had eRA) an association between low levels of

Personal non-commercial use only. The Journal of Rheumatology Copyright @ 2019 . All rights reserved. 
serum tumor necrosis factor- $\alpha(\mathrm{TNF}-\alpha)$ at baseline and response to MTX according to American College of Rheumatology 20 (ACR20) criteria at 6 months. No association was detected for interleukin $1 \beta$ (IL-1 $\beta$ ), IL-6, IL-8, IL-10, or IL-12 ${ }^{20}$. A similar association with serum TNF- $\alpha$ was found by another research group ${ }^{21}$. In a Chinese study of patients with eRA, it was shown that high serum levels of haptoglobin were associated with response to MTX therapy ${ }^{22}$. A study of treatment-naive eRA patients in India demonstrated that serum baseline levels of myeloid-related protein 8/14 were significantly higher in responders versus nonresponders to 4 months of MTX monotherapy, according to European League Against Rheumatism (EULAR) criteria $^{23}$. Despite many years of research, no biomarker has been validated or accepted as a routine clinical predictor for MTX treatment response.

The multibiomarker disease activity (MBDA) score is a commercially available test that is based on the serum levels of the following 12 protein molecules: vascular cell adhesion molecule 1 (VCAM-1), epidermal growth factor (EGF), vascular endothelial growth factor, IL-6, TNF receptor I (TNF-RI), matrix metalloproteinases 1 and 3 (MMP-1 and MMP-3), bone glycoprotein 39, leptin, resistin, serum amyloid A, and C-reactive protein (CRP). Previously, we showed predictive ability of the MBDA score for radiographic progression of joint damage in patients from the Swedish Pharmacotherapy (SWEFOT) clinical trial ${ }^{24,25}$. We also illustrated predictive ability of lower and higher levels of the MBDA score measured 3 months after MTX treatment initiation, for response to nonbiological and biological second-line therapy, respectively, in patients with MTX-IR ${ }^{26}$. In our present study, we investigated the associations of the individual components of the MBDA score at baseline with subsequent response to first-line treatment with MTX.

\section{MATERIALS AND METHODS}

Study population and outcomes. The SWEFOT trial (registration no. NCT00764725) enrolled 487 patients with eRA (symptom duration $\leq 1 \mathrm{yr}$ ), age $\geq 18$ years, and moderate/high disease activity score based on examination of 28 joints and erythrocyte sedimentation rate [28-joint count Disease Activity Score $(\mathrm{DAS} 28)>3.2]^{3}$. Patients started MTX monotherapy for the first 3 months, and those who achieved a low disease activity (LDA; DAS28 $\leq 3.2$ ) remained on the same therapy afterward. Patients with MTX-IR (DAS28 > 3.2) were randomized at Month 3 to either of 2 add-on intensified therapy groups: conventional triple therapy or anti-TNF (infliximab). In our study we evaluated associations of baseline biomarkers that constitute the MBDA score with primary (LDA) and secondary (EULAR good response $)^{27}$ outcomes at 3 months in 298 patients, selected based on available data.

The study was approved by the regional ethics committees of all participating units [Karolinska Institutet 02-211, Örebro 2002/202 500:16, Umeå 2002, Linköping 02-186, Uppsala Ups 02-241, Göteborg Gbg Ö 282-01, M 088-02, Lund LU 398-01, and Stockholm Central Ethical Review Board (EPN) 2005/1361, 2006/248-3]. All patients received and signed written informed consent about the use of their materials in future research.

MBDA score and component biomarkers. The MBDA score (Vectra DA) was developed by Crescendo Bioscience as a clinical disease activity monitoring tool in patients with RA. It was designed to correlate with
DAS28-CRP and it has a scale between 1 and 100, with higher values indicating more active disease. The serum samples were shipped to the company (Crescendo Bioscience) for analysis of the 12-component protein biomarkers and subsequently the MBDA score was calculated. The biomarkers were measured by electrochemiluminescence-based multiplex immunoassays on the Meso Scale Discovery Multi-Array platform ${ }^{28}$.

Statistical analyses. Baseline demographics and characteristics (including the MBDA score and the 12 comprising biomarkers) were compared between patients who achieved and who did not achieve LDA at 3 months. For continuous variables, Mann-Whitney U test was used and for categorical variables, chi-square or Fisher's exact test. Of the 12 biomarkers, those with p values $<0.2$ (VCAM-1, TNF-RI, IL-6, CRP, MMP-1, MMP-3, and leptin) were included in a multivariate logistic regression model to calculate $\mathrm{OR}$ with $95 \% \mathrm{CI}$ for the achievement of LDA at 3 months. Receiver-operating characteristic (ROC) curve analysis was thereafter performed on 4 biomarkers that remained significantly predictive in the stepwise multivariate model (VCAM-1, TNF-RI, CRP, and leptin), calculating areas under the curve (AUC) and defining cutoffs for high versus low values, based on the largest sum of sensitivity and specificity. After dichotomization of patients according to the generated cutoffs, proportions of patients achieving LDA or EULAR good response at 3 months were compared, using the chi-square test. The combined effect of the identified biomarkers as predictors of achievement of LDA or EULAR good response at 3 months was also studied by the generation of a combined biomarker score (see below). Thereafter, this combined biomarker score was included with previously known predictors [sex, age, smoking status, and Health Assessment Questionnaire (HAQ) score] of EULAR good response ${ }^{11}$ and with anticyclic citrullinated peptide antibodies (anti-CCP) status into a multivariate logistic regression model to assess its independence in association with primary and secondary outcomes. Finally, the combined biomarker score was analyzed with other predictors in a matrix model (using chi-square test), to demonstrate its additive value for predicting achievement of the primary and secondary outcome. In the matrix model, patients were dichotomized according to age based on ROC curve analysis ( $\leq 59$ and $>59 \mathrm{yrs})$, which was very close to a cutoff used by Saevarsdottir, et al, ( $\leq 60$ and $>60 \mathrm{yrs})$ based on the highest tertile ${ }^{11}$. The statistical analyses were done by IBM SPSS Statistics (version 24).

Combined biomarker score. The combined score was based on dichotomized levels of CRP, leptin, TNF-RI, and VCAM-1 (cutoffs between low and high categories were based on the ROC curve analysis described above) and had a range from 0 to 4 . Score 0 corresponded to patients with favorable category for all 4 biomarkers [CRP (low), leptin (low), TNF-RI (high), VCAM-1 (high); patients at lowest risk of nonresponse], score 1 corresponded to patients having 1 of 4 variables with unfavorable category (patients at low risk of nonresponse), score 2 corresponded to patients with 2 of 4 variables with unfavorable category (patients at moderate risk of nonresponse), score 3 corresponded to patients with 3 of 4 variables with unfavorable category (patients at high risk of nonresponse), and score 4 corresponded to patients with unfavorable category for all 4 biomarkers [CRP (high), leptin (high), TNF-RI (low), VCAM-1 (low); patients at highest risk of nonresponse].

In addition, a combined score was generated based on continuous data, in which contribution of each of the 4 biomarkers was accounted for according to their weights for association with treatment outcome.

\section{RESULTS}

Baseline characteristics. Baseline characteristics and demographic data are presented in Table 1. As shown previously, baseline variables and demographic data of patients with available MBDA data did not differ from those of all patients enrolled in the SWEFOT trial ${ }^{24}$. Of 298 disease-modifying antirheumatic drug (DMARD)-naive eRA patients, 104 achieved LDA after 3 months of MTX monotherapy (Table 1), of whom 101 had a EULAR good response. The analysis of 
Table 1. Baseline characteristics of patients with early RA from the SWEFOT trial.

\begin{tabular}{|c|c|c|c|}
\hline \multirow[t]{2}{*}{ Variables } & \multicolumn{3}{|c|}{ Stratified by Disease Activity (DAS28) at 3 Months of Followup } \\
\hline & $\begin{array}{c}\text { DAS } 28 \leq 3.2 \\
\mathrm{n}=104^{\mathrm{a}}\end{array}$ & $\begin{array}{c}\mathrm{DAS} 28>3.2 \\
\mathrm{n}=194^{\mathrm{b}}\end{array}$ & $\mathrm{p}$ \\
\hline \multicolumn{4}{|l|}{ Baseline characteristics } \\
\hline Female, n $(\%)$ & $60(58)$ & $154(79)$ & $<0.001$ \\
\hline Age, yrs & $61(51-69)$ & $55(44-62)$ & 0.001 \\
\hline Smoking, $\mathrm{n}(\%)$ & $19(24)$ & $47(26)$ & 0.780 \\
\hline Symptom duration, mos & $5(3-8)$ & $5(4-8)$ & 0.283 \\
\hline Anti-CCP-positive, n (\%) & $63(64)$ & $107(58)$ & 0.292 \\
\hline RF-positive, n (\%) & $73(71)$ & $124(65)$ & 0.274 \\
\hline Prednisolone use, n (\%) & $15(14)$ & $20(10)$ & 0.293 \\
\hline 28-swollen joint count & $9(7-13)$ & $11(7-15)$ & 0.087 \\
\hline 28-tender joint count & $6(4-10)$ & $10(6-15)$ & $<0.001$ \\
\hline $\mathrm{ESR}, \mathrm{mm} / \mathrm{h}$ & $28(15-42)$ & $36(24-62)$ & 0.001 \\
\hline $\mathrm{CRP}, \mathrm{mg} / \mathrm{l}$ & $15(9-33)$ & $20(9-53)$ & 0.033 \\
\hline PtGA (VAS 0-100 mm) & $50(29-67)$ & $63(43-77)$ & 0.001 \\
\hline Pain (VAS 0-100 mm) & $49(33-64)$ & $62(46-74)$ & $<0.001$ \\
\hline HAQ & $1.0(0.50-1.38)$ & $1.25(0.88-1.75)$ & $<0.001$ \\
\hline DAS28 & $5.2(4.6-5.9)$ & $5.9(5.3-6.4)$ & $<0.001$ \\
\hline \multicolumn{4}{|c|}{ Baseline protein biomarkers and MBDA score } \\
\hline VCAM-1, mg/l & $0.70(0.60-0.86)$ & $0.64(0.56-0.77)$ & 0.005 \\
\hline TNF-RI, $\mu \mathrm{g} / \mathrm{l}$ & $1.9(1.6-2.4)$ & $1.7(1.4-2.2)$ & 0.005 \\
\hline IL-6, ng/l & $49(22-97)$ & $67(29-150)$ & 0.044 \\
\hline $\mathrm{CRP}, \mathrm{mg} / \mathrm{l}$ & $20(8-43)$ & $27(10-110)$ & 0.045 \\
\hline MMP-1, $\mu \mathrm{g} / 1$ & $9.35(5.87-15)$ & $11(6.48-18)$ & 0.067 \\
\hline MMP-3, $\mu \mathrm{g} / 1$ & $48(28-82)$ & $56(29-123)$ & 0.105 \\
\hline Leptin, $\mu \mathrm{g} / 1$ & $9.25(3.58-14)$ & $10.50(4.60-20.25)$ & 0.108 \\
\hline VEGF, ng/l & $405(265-600)$ & $390(250-590)$ & 0.719 \\
\hline Resistin, $\mu \mathrm{g} / 1$ & $6.60(5.35-8.78)$ & $6.80(5.10-8.68)$ & 0.857 \\
\hline YKL-40, $\mu \mathrm{g} / 1$ & $85(54-120)$ & $79(57-130)$ & 0.862 \\
\hline EGF, ng/l & $160(103-258)$ & $170(100-253)$ & 0.903 \\
\hline $\mathrm{SAA}, \mathrm{mg} / \mathrm{l}$ & $20(7-46)$ & $17(4-73)$ & 0.990 \\
\hline MBDA score & $59(47-66)$ & $59(49-74)$ & 0.143 \\
\hline
\end{tabular}

Data are expressed in median (IQR) unless otherwise specified. ${ }^{a}$ Missing patients from DAS2 $8 \leq 3.2$ column: smoking $(\mathrm{n}=25)$, anti-CCP $(\mathrm{n}=6)$, and RF $(\mathrm{n}=1) \cdot{ }^{\mathrm{b}}$ Missing patients from DAS28 > 3.2 column: smoking $(\mathrm{n}=11)$, anti-CCP $(\mathrm{n}=9)$, RF, PtGA, pain $(\mathrm{n}=2), \mathrm{HAQ}(\mathrm{n}=4)$, and DAS28 $(\mathrm{n}=3)$. RA: rheumatoid arthritis; IQR: interquartile range; anti-CCP: anticyclic citrullinated peptide; RF: rheumatoid factor; ESR: erythrocyte sedimentation rate; CRP: C-reactive protein; PtGA: patient's global assessment of disease activity score; VAS: visual analog scale; HAQ: Health Assessment Questionnaire; DAS28: 28-joint count Disease Activity Score; MBDA: multibiomarker disease activity; VCAM-1: vascular cell adhesion molecule 1; TNF-RI: tumor necrosis factor receptor I; IL-6: interleukin 6; MMP: matrix metalloproteinase; VEGF: vascular endothelial growth factor; YKL-40: human cartilage glycoprotein-39; EGF: epidermal growth factor; SAA: serum amyloid A; SWEFOT: Swedish Pharmacotherapy trial.

baseline characteristics between EULAR responders and nonresponders to MTX was previously published based on a larger subset $(n=405)$ from the SWEFOT trial ${ }^{11}$.

As shown previously ${ }^{29}$, the MBDA score at baseline was not significantly different between patients achieving and not achieving LDA at 3 months (Table 1). Of the 12 component proteins at baseline, CRP and IL-6 were significantly lower, and TNF-RI and VCAM-1 were significantly higher among patients who achieved LDA at 3 months compared with MTX-IR (Table 1).

Molecular predictors of achievement of low DAS28. Individual biomarkers that had $\mathrm{p}<0.2$ were included in the multivariate logistic regression analysis (Table 2). After stepwise multivariate analysis, higher levels of CRP and leptin were independently associated with lower likelihood of achieving LDA (OR 0.99, 95\% CI 0.98-0.99, and OR 0.97, 95\% CI 0.95-0.99, respectively), and higher levels of TNF-RI or VCAM-1 were associated with increased likelihood of achieving LDA at 3 months (OR 2.5, 95\% CI 1.4-4.3, and OR 8.2, 95\% CI 1.5-45.6, respectively; Table 2).

Similar results were observed for the secondary outcome measure (Supplementary Table 1, available from the authors on request).

ROC curve analysis and dichotomization of CRP, leptin, $T N F-R I$, and VCAM-1. The ROC curve analyses of CRP, leptin, TNF-RI, and VCAM-1 yielded AUC of 0.56-0.60 (Figure 1). The 95\% CI of the AUC for leptin included 0.5 $(\mathrm{p}=0.108$; Figure 1A), while the AUC for CRP, TNF-RI, and

Personal non-commercial use only. The Journal of Rheumatology Copyright (C) 2019. All rights reserved. 
Table 2. Multivariate logistic regression of protein biomarkers at baseline for prediction of low DAS28 at 3 months.

\begin{tabular}{lcc}
\hline Biomarkers & OR & $95 \%$ CI \\
\hline VCAM-1 (per mg/l increase) & $\mathbf{6 . 7 0}$ & $1.17-38.62$ \\
TNF-RI (per $\mu \mathrm{g} / 1$ increase) & $\mathbf{3 . 1 0}$ & $1.70-5.71$ \\
IL-6 (per ng/l increase) & 0.99 & $0.99-1.00$ \\
CRP (per mg/l increase) & $\mathbf{0 . 9 9}$ & $0.98-0.99$ \\
MMP-1 (per $\mu \mathrm{g} / 1$ increase) & 0.98 & $0.94-1.01$ \\
MMP-3 (per $\mu \mathrm{g} / 1$ increase) & 1.00 & $0.99-1.00$ \\
Leptin (per $\mu \mathrm{g} / \mathrm{l}$ increase) & $\mathbf{0 . 9 7}$ & $0.95-0.99$ \\
Results after stepwise logistic regression analysis & \\
VCAM-1 (per mg/l increase) & $\mathbf{8 . 1 9}$ & $1.47-45.65$ \\
TNF-RI (per $\mu \mathrm{g} / 1$ increase) & $\mathbf{2 . 4 8}$ & $1.43-4.31$ \\
CRP (per mg/l increase) & $\mathbf{0 . 9 9}$ & $0.98-0.99$ \\
Leptin (per $\mu \mathrm{g} / 1$ increase) & $\mathbf{0 . 9 7}$ & $0.95-0.99$ \\
\hline
\end{tabular}

Values in bold face are statistically significant. DAS28: 28-joint count Disease Activity Score; VCAM-1: vascular cell adhesion molecule 1; TNF-RI: tumor necrosis factor receptor I; IL-6: interleukin 6; CRP: C-reactive protein; MMP: matrix metalloproteinase.

VCAM- 1 were statistically significant $(\mathrm{p}=0.045,0.005$, and 0.005 , respectively; Figure 1A and 1B). These 4 biomarkers were dichotomized to low and high levels, based on the highest sum of sensitivity and specificity and resulted in the following cutoffs: for CRP $\leq$ or $>51.5 \mathrm{mg} / \mathrm{l}$, for leptin $\leq$ or $>14.5 \mu \mathrm{g} / \mathrm{l}$, for TNF-RI $\leq$ or $>1.75 \mu \mathrm{g} / \mathrm{l}$, and for VCAM- 1 $\leq$ or $>0.605 \mathrm{mg} / \mathrm{l}$.

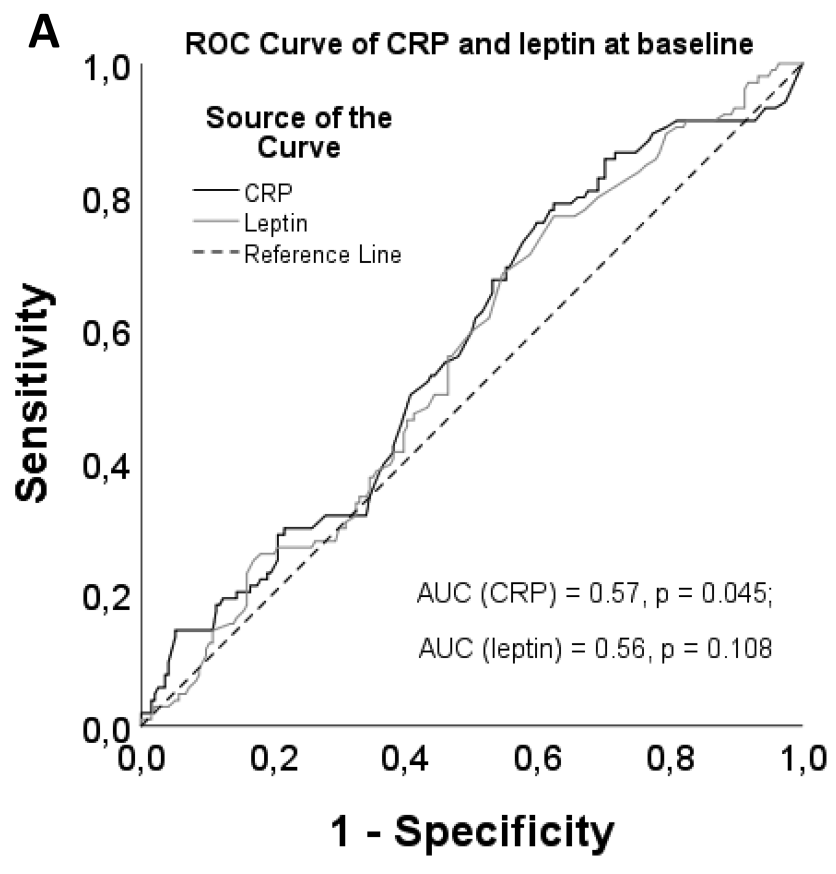

Diagonal segments are produced by ties.
Proportions of patients who achieved low DAS28 at 3 months among those with low versus high levels of biomarkers. Of patients with low CRP at baseline $(\mathrm{n}=203)$, $40 \%$ reached LDA after 3 months of MTX monotherapy, while of those with high levels of CRP $(n=95)$ the proportion was $23 \%(\mathrm{p}=0.004$; Figure $2 \mathrm{~A})$. Similar proportions of patients achieving LDA were observed when comparing patients with low versus high leptin levels (40\% vs $25 \%$, respectively, $\mathrm{p}=0.011$; Figure $2 \mathrm{~B}$ ). The reverse relationship was seen when patients were dichotomized according to TNF-RI or VCAM-1: $27 \%$ vs $43 \%(\mathrm{p}=0.004)$, and $25 \%$ vs $41 \%(\mathrm{p}=0.004)$, respectively (Figure $2 \mathrm{C}$ and 2D).

As a secondary outcome we used EULAR good versus moderate/no response with similar findings (Supplementary Figure 1, available from the authors on request).

Prediction of low DAS28 at 3 months using a combined biomarker score at baseline. Based on dichotomized categories of the 4 biomarkers indicated above, we calculated a combined biomarker score ranging from 0 (patients with favorable categories for all 4 biomarkers, therefore associated with highest chance of response to MTX) to 4 (patients with unfavorable categories for all 4 biomarkers, therefore associated with highest risk of nonresponse). The combined biomarker score at baseline was negatively associated with treatment outcomes at 3 months (Figure 3). Patients in the lowest risk group for nonresponse $($ score $=0$ ) had the highest

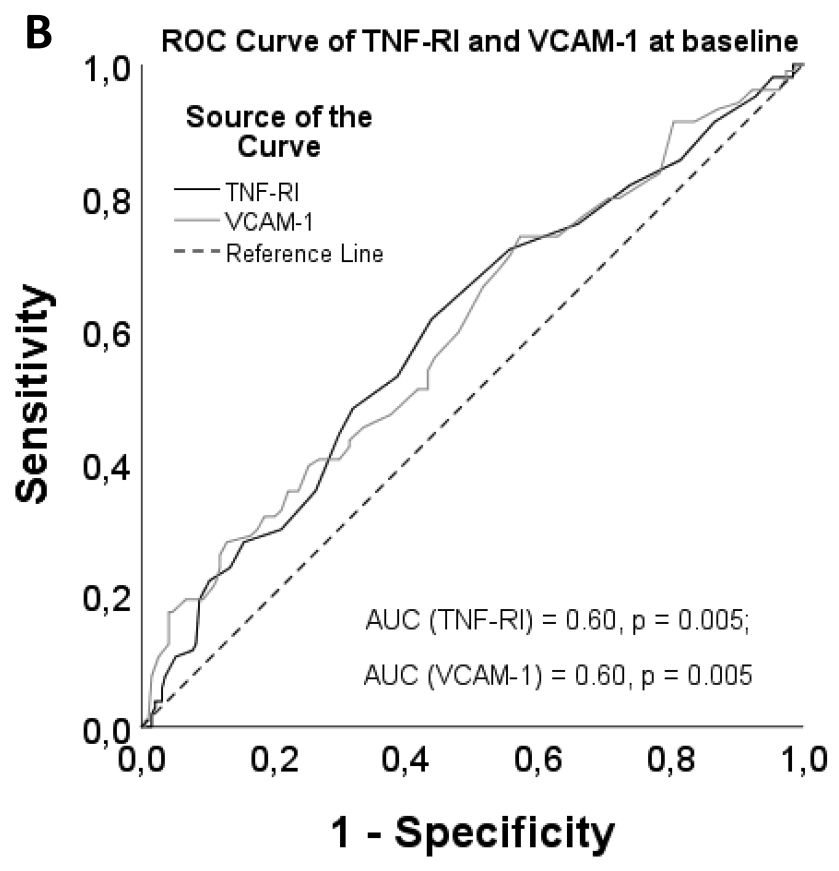

Diagonal segments are produced by ties.

Figure 1. ROC curve analysis of serum biomarkers at baseline using low DAS28 at 3 months as an outcome. ROC curve and AUC of (A) CRP (black line) and leptin (grey line), and (B) TNF-RI (black line) and VCAM-1 (grey line). AUC: area under the curve; CRP: C-reactive protein; DAS28: 28-joint count Disease Activity Score; TNF-RI: tumor necrosis factor receptor I; VCAM-1: vascular cell adhesion molecule 1; ROC: receiver-operating characteristic. 

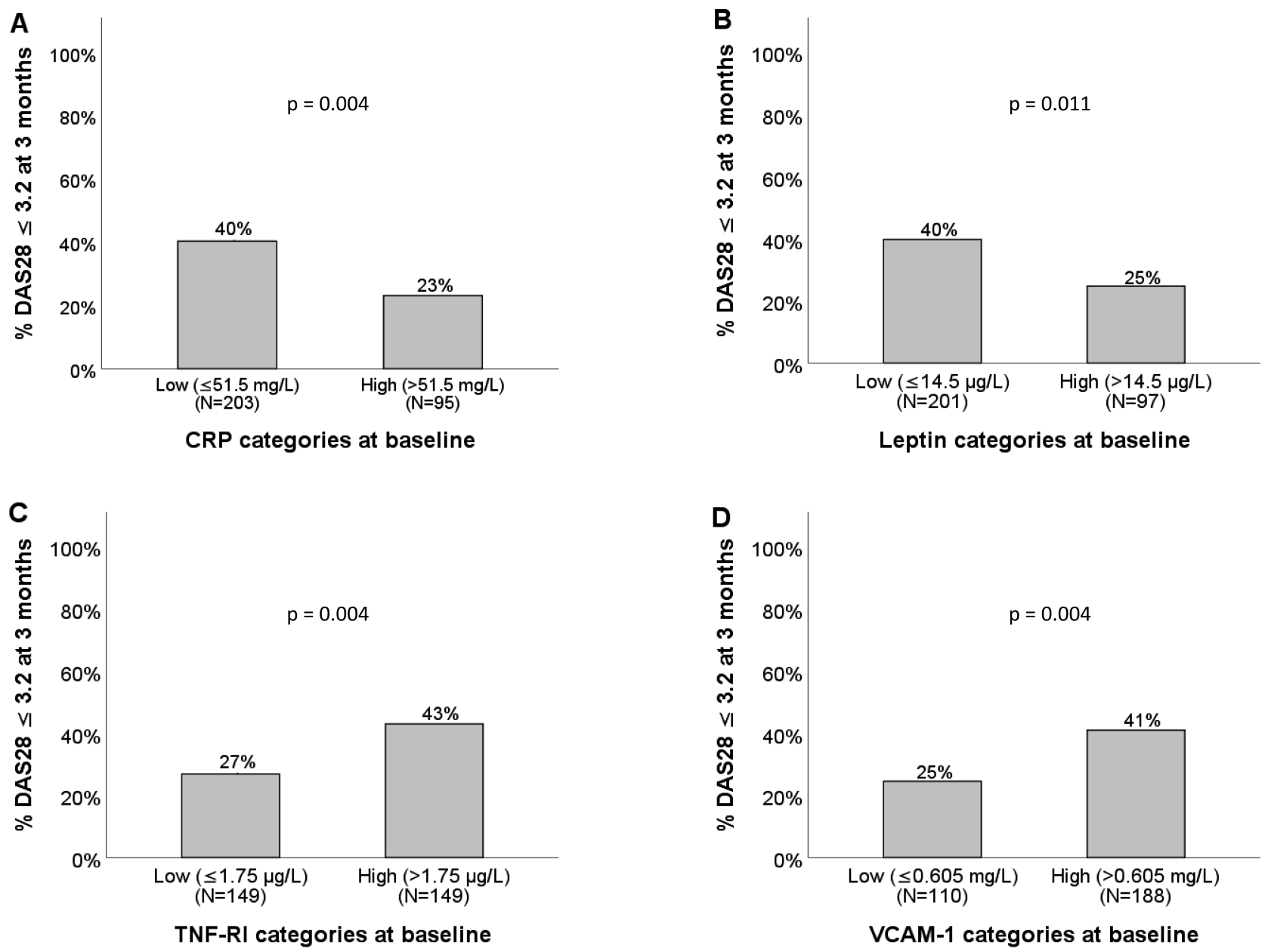

Figure 2. Proportions of patients with early rheumatoid arthritis achieving low disease activity after 3 months of MTX monotherapy, stratified for different biomarkers. Proportions of patients with low DAS28 in patients dichotomized according to (A) CRP, (B) leptin, (C) TNF-RI, and (D) VCAM-1. DAS28: 28-joint count Disease Activity Score; CRP: C-reactive protein; MTX: methotrexate; TNF-RI: tumor necrosis factor receptor I; VCAM-1: vascular cell adhesion molecule 1.

proportion of LDA achievement at 3 months $(74 \%)$, while for those with score $=1(\mathrm{n}=109)$, the proportion was $38 \%$ $(\mathrm{p}<0.0001)$; for score $=2,27 \%(\mathrm{p}<0.0001)$; for those with score $=3,13 \%(\mathrm{p}<0.0001)$; and in the highest score group $($ score $=4), 0 \%(p=0.003 ;$ Figure $3 \mathrm{~A})$.

Similar results were also obtained when using the secondary outcome measure of EULAR good response at 3 months, instead of LDA (Figure 3B).

Additional value of the combined biomarker score to previously described predictors for achievement of low DAS28 and EULAR good response. In univariate logistic regression analysis of the combined biomarker score and baseline characteristics [rheumatoid factor (RF), anti-CCP, sex, age, smoking status, and HAQ], sex, age, HAQ, and the combined biomarker score were significantly associated with treatment outcomes at 3 months (Table 3, and Supplementary Table 2, available from the authors on request). After including all these variables (except for RF, because of its correlation with
anti-CCP) in a multivariate logistic regression model, age, $\mathrm{HAQ}$, and combined biomarker score were independently associated with treatment outcome (Table 3, and Supplementary Table 2, available from the authors on request). We did not adjust for baseline DAS28 in the multivariate model because the outcome measure was based on that, but when stratified for baseline DAS28 into high (> 5.1) and moderate (> 3.2-5.1), there was a similar pattern in both subgroups (data not shown). A sensitivity analysis using stepwise regression yielded the same independent predictors (Table 3, and Supplementary Table 2, available from the authors on request).

Comparison within each category of age and HAQ score (using categories from a previous publication ${ }^{11}$ ) still showed higher probability of LDA and EULAR good response in patients with lower compared with higher combined biomarker score; in some subgroups, the difference between patients with score $=0$ and score $=1,2$, or 3 was statistically

Personal non-commercial use only. The Journal of Rheumatology Copyright @) 2019. All rights reserved. 
A

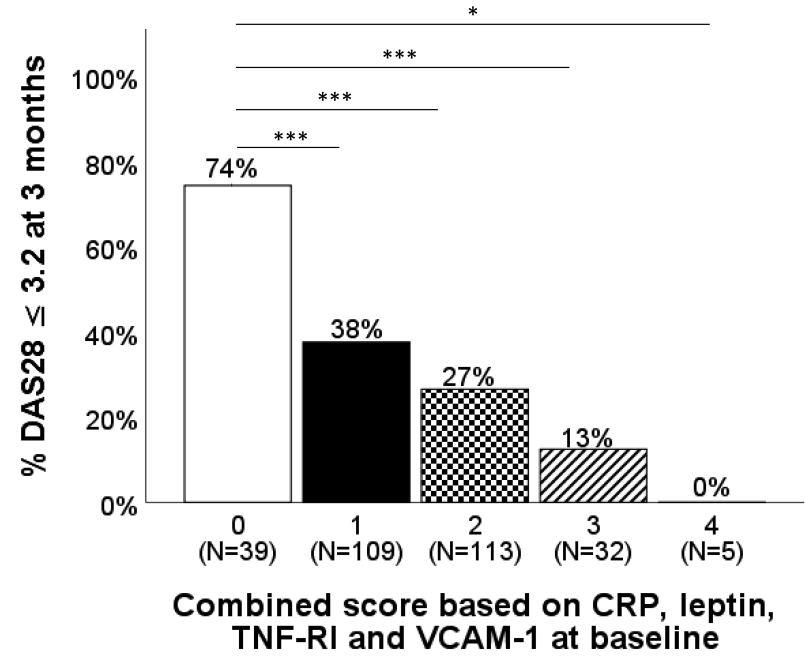

B

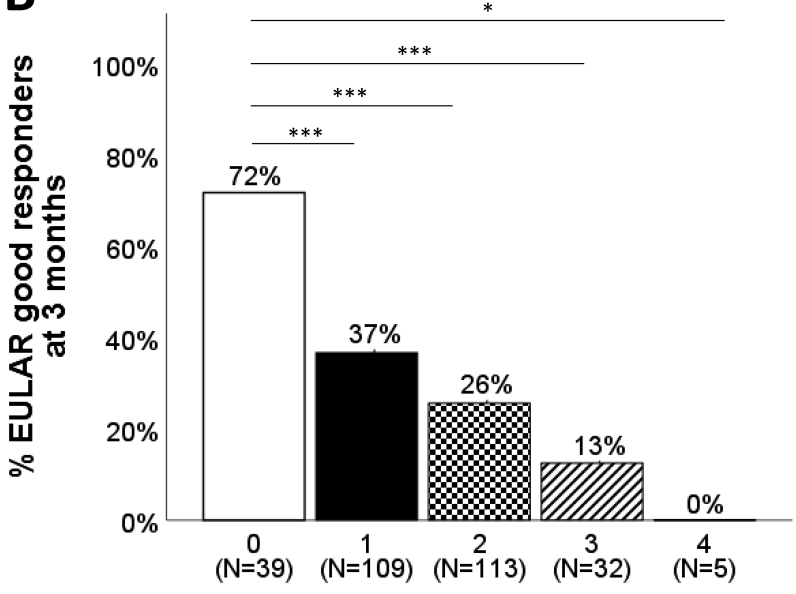

Combined score based on CRP, leptin, TNF-RI and VCAM-1 at baseline

$$
\begin{aligned}
& \text { Groups: } \\
& \square \text { low CRP\&leptin AND high TNF-RI\&VCAM-1; } \\
& 3 \text { favourale categories and } 1 \text { unfavourable; } \\
& 2 \text { favourable categories and } 2 \text { unfavourable; } \\
& \square 1 \text { favourable category and } 3 \text { unfavourable; } \\
& \text { III high CRP\&leptin AND low TNF-RI\&VCAM-1; } \\
& * p<0.01, * * * p<0.0001
\end{aligned}
$$

\begin{tabular}{|c|c|c|c|c|}
\hline \multirow[t]{2}{*}{ Variables } & \multicolumn{2}{|c|}{ Univariate } & \multicolumn{2}{|c|}{ Multivariate } \\
\hline & OR & $95 \% \mathrm{CI}$ & OR & $95 \% \mathrm{CI}$ \\
\hline RF-positive ${ }^{a}$ & 1.33 & $0.79-2.24$ & 1.35 & $0.71-2.57$ \\
\hline Anti-CCP-positive & 1.31 & $0.79-2.18$ & 1.65 & $0.87-3.14$ \\
\hline Sex, male & 2.82 & $1.67-4.76$ & 1.76 & $0.88-3.50$ \\
\hline Age (per yr increase) & 1.03 & $1.01-1.05$ & 1.03 & $1.01-1.05$ \\
\hline Current smoking (yes) & 0.92 & $0.50-1.69$ & 0.78 & $0.38-1.64$ \\
\hline HAQ (per unit increase) & 0.36 & $0.23-0.57$ & 0.38 & $0.22-0.65$ \\
\hline Combined biomarker score (per unit increase) ${ }^{\mathrm{b}}$ & 0.40 & $0.29-0.55$ & 0.43 & $0.29-0.65$ \\
\hline \multicolumn{5}{|l|}{ Results after stepwise logistic regression analysis } \\
\hline Sex, male & & & 1.64 & $0.90-2.98$ \\
\hline Age (per yr increase) & & & 1.03 & $1.01-1.05$ \\
\hline HAQ (per unit increase) & & & 0.35 & $0.22-0.58$ \\
\hline Combined biomarker score (per unit increase) & & & 0.44 & $0.31-0.63$ \\
\hline
\end{tabular}

Figure 3. Proportions of patients with early rheumatoid arthritis achieving low DAS28 or EULAR good response after 3 months of MTX monotherapy, stratified for the combined biomarker score. Proportions of patients with (A) low DAS28 or (B) EULAR good response within subsets based on the combined biomarker score: combined score $=0$ (white bars), combined score $=1$ (black bars), combined score $=2$ (bars with checkered pattern), combined scores $=3$ (bars with diagonal lines), and combined score $=4$ (bars with vertical lines). DAS28: 28-joint count Disease Activity Score; EULAR: European League Against Rheumatism; CRP: C-reactive protein; MTX: methotrexate; TNF-RI: tumor necrosis factor receptor I; VCAM-1: vascular cell adhesion molecule 1.

Table 3. Univariate and multivariate logistic regression of combined biomarker score and some baseline predictors of low DAS28 at 3 months.

Values in bold face are statistically significant. ${ }^{a}$ RF was excluded from multivariate model because of its collinearity with anti-CCP. ${ }^{b}$ OR for the combined biomarker score in univariate analysis indicates that for each unit increase, the odds of achievement of LDA decrease by $60 \%$. Similarly, in multivariate model, after considering for other predictors (anti-CCP, sex, age and smoking), the odds of LDA decrease by $56 \%$ for each unit increase in the combined biomarker score. RF: rheumatoid factor; anti-CCP: anticyclic citrullinated peptide; HAQ: Health Assessment Questionnaire; DAS28: 28-joint count Disease Activity Score; LDA: low disease activity.

significant among patients within the highest category of HAQ score (Supplementary Figure 2, available from the authors on request).

\section{DISCUSSION}

In our current study, we evaluated baseline levels of all the 12 individual biomarkers included in a commercially 
available blood multibiomarker test (MBDA score) as potential predictors of subsequent response to 3 months of MTX monotherapy in DMARD-naive eRA patients from the SWEFOT trial. Multivariate logistic regression assessment of biomarkers that had the strongest univariate associations with treatment outcome revealed 4 independent predictors: low levels of CRP and leptin as well as high levels of TNF-RI and VCAM-1 were associated with achievement of low DAS28 and EULAR good response.

The MBDA score was developed and validated for assessment and monitoring of clinical disease activity, but not prediction of later disease activity, in patients with RA. It has a range from 1 to 100 and can be categorized as follows: low $(<30)$, moderate $(30-44)$, and high ( $>44)$. It has been shown in different trials (including SWEFOT) that the MBDA score is predictive for radiographic progression $^{24,30,31}$. In MTX-IR from the SWEFOT trial, we also showed that the MBDA score analyzed at 3 months - just before treatment escalation to triple therapy or infliximab was differentially associated with clinical response to each of the second-line therapies ${ }^{26}$. At baseline, however, the MBDA score was not significantly associated with response to 3 months of MTX monotherapy ${ }^{29}$ (Table 1). Regarding data from other studies, in the Nested-1 cohort it was shown that changes in the MBDA score already at the second week of MTX or anti-TNF therapy (pooled data) were associated with clinical response (EULAR good response criteria based on DAS28-CRP or ACR50 response) at weeks 6 or $12^{32}$. However, because of lack in statistical power, the analyses could not be done separately for each of the therapy arms. In the CAMERA trial, in which patients were mainly on MTX with allowance of nonsteroidal antiinflammatory drugs and intraarticular injection of glucocorticoids (when necessary), the MBDA score was able to discriminate patients in remission/LDA (DAS28-CRP $\leq 2.7$ ) versus those with moderate/high disease activity ${ }^{33}$. All biomarkers except for EGF, leptin, and VCAM-1 were significantly correlated with DAS28-CRP or DAS28.

In our present study, we found baseline levels of CRP, leptin, TNF-RI, and VCAM-1 to be independently associated with clinical response to MTX at 3 months. However, data from other studies of these individual biomarkers are inconsistent, some showing poor or no association of baseline CRP with clinical response $\mathrm{s}^{5,23,34}$ and others illustrating predictive ability ${ }^{35}$. It is worth commenting on the method used to measure CRP. In the SWEFOT trial, CRP was measured in clinical routine laboratories during inclusion and followup. The CRP for the MBDA score was measured separately by a more sensitive method. In our study, CRP data from both sources showed similar associations with treatment outcome (compare Table 1 upper and lower parts).

While CRP is used as an inflammatory marker in routine care, leptin is not studied as much. Being a lipid hormone, leptin is produced mainly by white adipose tissue and regulates appetite by inhibition of neuropeptide Y secretion $^{36,37}$. A study on 16 female patients with established RA and 16 healthy women did not reveal any difference in plasma leptin levels between these 2 groups $^{38}$, and no correlations were observed of leptin with CRP, ESR, or DAS28 before therapy. Similar nonlinearity of leptin with CRP among 75 patients with RA (of which 35 had DAS28 $\leq 3.2$ ) was observed by Iranian researchers ${ }^{39}$. In our study, leptin had a weak inverse correlation with CRP, which may be because our patients were DMARD-naive as opposed to the 2 examples mentioned above, in which patients were receiving treatment leading to significant decreases of CRP but not leptin levels. Even though lower levels of both leptin and CRP at baseline in our study were significantly associated with subsequent response to MTX, the multivariate analysis still illustrated their independence from each other. However, sex should be considered because leptin is significantly higher in females compared with males, and female sex has been shown to be associated with poorer response. Therefore, we adjusted for sex and presented our findings stratified for sex in the risk matrices (Supplementary Figure 2, available from the authors on request).

TNF- $\alpha$, one of the key players in the pathology of RA, realizes its proinflammatory function through 2 types of cell surface-bound receptors: TNF-RI and TNF-RII. Both may be released from the cell surface and circulate in the blood during inflammation, reducing the intracellular signal transduction and regulating inflammation. Xanthoulea, et al, for example, have demonstrated on a knockout mice model that inability to cleave the membrane TNF receptors led to better antibacterial defense, which, however, was accompanied by a shift in equilibrium of the immune system toward pathological inflammatory conditions ${ }^{40}$. Taking into consideration that an increased level of soluble TNF-RI might be an indicator of increased inflammation and/or TNF levels, as well as that MTX therapy may reduce levels of TNF $41,42,43,44$, it becomes logical to assume that higher levels of TNF-RI in serum will be associated with higher likelihood of response to MTX, compared with those patients who have active disease but lower levels of TNF-RI.

VCAM-1 expression in endothelial cells is upregulated during inflammation. Its role is to facilitate adhesion of leukocytes and their migration from the bloodstream to the affected tissue. We observed a higher likelihood of achievement of good clinical outcome after 3 months of MTX monotherapy in patients with higher, as compared to lower, baseline serum levels of VCAM-1. Because all these patients had eRA and were DMARD-naive, we assume that those with higher levels of VCAM-1 had different mechanisms driving their disease, where VCAM-1 plays a more important role compared with those with lower levels. Subsequently, if the treatment decreases the levels of VCAM-1, most likely patients with higher levels of the biomarker would benefit more from such therapy. There are

Personal non-commercial use only. The Journal of Rheumatology Copyright (C) 2019. All rights reserved. 
several studies showing that MTX decreases serum levels of VCAM-1 ${ }^{45,46,47}$. And in support of our hypothesis, Kraan and colleagues have noticed that patients who received MTX treatment and achieved ACR20 response had greater reduction of expression of VCAM-1 in synovial tissue compared with nonresponders ${ }^{46}$. In our study, we similarly observed a significantly greater reduction of soluble VCAM-1 at 3 months in responders compared to nonresponders (data not shown).

Because these 4 biomarkers did not show collinearity, we combined them after dichotomization into a single score, ranging from 0 to 4 and indicating patients at lowest to highest risk of not responding to MTX, respectively. An analysis of a combined score based on continuous data demonstrated similar results for association with treatment outcome (Supplementary Figure 3, available from the authors on request). After adjusting for previously shown baseline predictors ${ }^{11}$, the combined biomarker score remained an independent predictor of both LDA and EULAR good response at 3 months. Because leptin has a strong collinearity with sex, and age and HAQ were significant predictors, we further stratified the analyses for the biomarker score using those 2 fundamental variables, as presented in the risk matrices (Supplementary Figure 2, available from the authors on request). We found strong and clinically meaningful differences in the likelihood of LDA and EULAR response, especially in patients with high HAQ score, although numbers were limited in certain subgroups.

The size of the study group as well as the posthoc design are the main limitations of our study. Another limitation is that no standard cutoff values for the 4 biomarkers are available, so we used ROC curve analysis for dichotomization. Therefore, these threshold values need to be validated in another RA cohort.

The strength of our current study is the SWEFOT trial design, because the patients were recruited with very limited selection bias, as close as possible to real-life situations. Also, inclusion of DMARD-naive patients with eRA allowed us to evaluate the treatment outcome caused purely by MTX monotherapy, with only a minority of patients (12\%) receiving low-dose cortisone.

Lower baseline levels of CRP and leptin as well as higher baseline levels of TNF-RI and VCAM-1 were associated, independently from each other, with higher likelihood for response to MTX monotherapy in patients with eRA. Combination of these 4 biomarkers increased the predictive value of response to MTX for patients in addition to clinical baseline factors. If validated, these biomarkers could become a useful complement when choosing the treatment strategy for patients with eRA.

\section{ACKNOWLEDGMENT}

We thank all trial participants, nurses, and rheumatologists who made the SWEFOT trial possible. In addition, we are grateful to Crescendo Bioscience for analysis of the serum samples and Dr. C.C. Hwang for statistical review.

\section{REFERENCES}

1. Smolen JS, Landewe R, Breedveld FC, Buch M, Burmester G, Dougados $\mathrm{M}$, et al. EULAR recommendations for the management of rheumatoid arthritis with synthetic and biological disease-modifying antirheumatic drugs: 2013 update. Ann Rheum Dis 2014;73:492-509.

2. Singh JA, Furst DE, Bharat A, Curtis JR, Kavanaugh AF, Kremer JM, et al. 2012 Update of the 2008 American College of Rheumatology recommendations for the use of disease-modifying antirheumatic drugs and biologic agents in the treatment of rheumatoid arthritis. Arthritis Care Res 2012;64:625-39.

3. van Vollenhoven RF, Ernestam S, Geborek P, Petersson IF, Coster L, Waltbrand $\mathrm{E}$, et al. Addition of infliximab compared with addition of sulfasalazine and hydroxychloroquine to methotrexate in patients with early rheumatoid arthritis (Swefot trial): 1-year results of a randomised trial. Lancet 2009;374:459-66.

4. Hider SL, Buckley C, Silman AJ, Symmons DP, Bruce IN. Factors influencing response to disease modifying antirheumatic drugs in patients with rheumatoid arthritis. J Rheumatol 2005;32:11-6.

5. Hider SL, Silman AJ, Thomson W, Lunt M, Bunn D, Symmons DP. Can clinical factors at presentation be used to predict outcome of treatment with methotrexate in patients with early inflammatory polyarthritis? Ann Rheum Dis 2009;68:57-62

6. Drouin J, Haraoui B; 3e Initiative Group. Predictors of clinical response and radiographic progression in patients with rheumatoid arthritis treated with methotrexate monotherapy. J Rheumatol 2010;37:1405-10.

7. Ranganathan $P$. The challenges of methotrexate pharmacogenetics in rheumatoid arthritis. Pharmacogenomics 2012;13:377.

8. Bansard C, Lequerre T, Daveau M, Boyer O, Tron F, Salier JP, et al. Can rheumatoid arthritis responsiveness to methotrexate and biologics be predicted? Rheumatology 2009;48:1021-8.

9. Wessels JA, van der Kooij SM, le Cessie S, Kievit W, Barerra P, Allaart CF, et al; Pharmacogenetics Collaborative Research Group. A clinical pharmacogenetic model to predict the efficacy of methotrexate monotherapy in recent-onset rheumatoid arthritis. Arthritis Rheum 2007;56:1765-75.

10. Hoekstra M, van Ede AE, Haagsma CJ, van de Laar MA, Huizinga TW, Kruijsen MW, et al. Factors associated with toxicity, final dose, and efficacy of methotrexate in patients with rheumatoid arthritis. Ann Rheum Dis 2003;62:423-6.

11. Saevarsdottir S, Wallin H, Seddighzadeh M, Ernestam S, Geborek P, Petersson IF, et al; SWEFOT Trial Investigators Group. Predictors of response to methotrexate in early DMARD naive rheumatoid arthritis: results from the initial open-label phase of the SWEFOT trial. Ann Rheum Dis 2011;70:469-75.

12. Saevarsdottir S, Wedren S, Seddighzadeh M, Bengtsson C, Wesley A, Lindblad S, et al. Patients with early rheumatoid arthritis who smoke are less likely to respond to treatment with methotrexate and tumor necrosis factor inhibitors: observations from the Epidemiological Investigation of Rheumatoid Arthritis and the Swedish Rheumatology Register cohorts. Arthritis Rheum 2011;63:26-36.

13. Papadopoulos NG, Alamanos Y, Voulgari PV, Epagelis EK, Tsifetaki $\mathrm{N}$, Drosos AA. Does cigarette smoking influence disease expression, activity and severity in early rheumatoid arthritis patients? Clin Exp Rheumatol 2005;23:861-6

14. Manfredsdottir VF, Vikingsdottir T, Jonsson T, Geirsson AJ, Kjartansson O, Heimisdottir M, et al. The effects of tobacco smoking and rheumatoid factor seropositivity on disease activity and joint damage in early rheumatoid arthritis. Rheumatology. 2006;45:734-40.

15. Saag KG, Cerhan JR, Kolluri S, Ohashi K, Hunninghake GW, Schwartz DA. Cigarette smoking and rheumatoid arthritis severity. Ann Rheum Dis 1997;56:463-9. 
16. Wolfe F. The effect of smoking on clinical, laboratory, and radiographic status in rheumatoid arthritis. J Rheumatol 2000;27:630-7.

17. Anderson JJ, Wells G, Verhoeven AC, Felson DT. Factors predicting response to treatment in rheumatoid arthritis: the importance of disease duration. Arthritis Rheum 2000;43:22-9.

18. Ma MH, Ibrahim F, Walker D, Hassell A, Choy EH, Kiely PD, et al. Remission in early rheumatoid arthritis: predicting treatment response. J Rheumatol 2012;39:470-5.

19. Aletaha D, Funovits J, Keystone EC, Smolen JS. Disease activity early in the course of treatment predicts response to therapy after one year in rheumatoid arthritis patients. Arthritis Rheum 2007;56:3226-35.

20. Maillefert JF, Puechal X, Falgarone G, Lizard G, Ornetti P, Solau E, et al; Réseau Rhumato Study Group. Prediction of response to disease modifying antirheumatic drugs in rheumatoid arthritis. Joint Bone Spine 2010;77:558-63.

21. De Groof A, Ducreux J, Humby F, Nzeusseu Toukap A, Badot V, Pitzalis $\mathrm{C}$, et al. Higher expression of TNF $\alpha$-induced genes in the synovium of patients with early rheumatoid arthritis correlates with disease activity, and predicts absence of response to first line therapy. Arthritis Res Ther 2016;18:19.

22. Tan W, Wang F, Guo D, Ke Y, Shen Y, Lv C, et al. High serum level of haptoglobin is associated with the response of 12 weeks methotrexate therapy in recent-onset rheumatoid arthritis patients. Int J Rheum Dis 2016;19:482-9.

23. Patro PS, Singh A, Misra R, Aggarwal A. Myeloid-related protein 8/14 levels in rheumatoid arthritis: marker of disease activity and response to methotrexate. J Rheumatol 2016;43:731-7.

24. Hambardzumyan K, Bolce R, Saevarsdottir S, Cruickshank SE, Sasso EH, Chernoff D, et al. Pretreatment multi-biomarker disease activity score and radiographic progression in early RA: results from the SWEFOT trial. Ann Rheum Dis 2015;74:1102-9.

25. Hambardzumyan K, Bolce RJ, Saevarsdottir S, Forslind K, Wallman JK, Cruickshank SE, et al. Association of a multibiomarker disease activity score at multiple time-points with radiographic progression in rheumatoid arthritis: results from the SWEFOT trial. RMD Open 2016;2:e00197.

26. Hambardzumyan K, Saevarsdottir S, Forslind K, Petersson IF, Wallman $\mathrm{JK}$, Ernestam S, et al. A multi-biomarker disease activity score and the choice of second-line therapy in early rheumatoid arthritis after methotrexate failure. Arthritis Rheumatol 2017;69:953-63.

27. van Gestel AM, Prevoo ML, van 't Hof MA, van Rijswijk MH, van de Putte LB, van Riel PL. Development and validation of the European League Against Rheumatism response criteria for rheumatoid arthritis. Comparison with the preliminary American College of Rheumatology and the World Health

Organization/International League Against Rheumatism Criteria. Arthritis Rheum 1996;39:34-40.

28. Eastman PS, Manning WC, Qureshi F, Haney D, Cavet G, Alexander $\mathrm{C}$, et al. Characterization of a multiplex, 12-biomarker test for rheumatoid arthritis. J Pharm Biomed Anal 2012;70:415-24.

29. Hambardzumyan K, Saevarsdottir S, Bolce R, Forslind K, Ernestam S, Petersson I, et al. FRI0061 Multi-biomarker disease activity (MBDA) score and the 12 individual biomarkers in early rheumatoid arthritis patients relate differentially to clinical response and radiographic progression: results from the Swefot trial [abstract]. Ann Rheum Dis 2013;72:A388-9.

30. van der Helm-van Mil AH, Knevel R, Cavet G, Huizinga TW, Haney DJ. An evaluation of molecular and clinical remission in rheumatoid arthritis by assessing radiographic progression. Rheumatology 2013;52:839-46.

31. Markusse IM, Dirven L, van den Broek M, Bijkerk C, Han KH, Ronday HK, et al. A multibiomarker disease activity score for rheumatoid arthritis predicts radiographic joint damage in the BeSt study. J Rheumatol 2014;41:2114-9.
32. Curtis JR, van der Helm-van Mil AH, Knevel R, Huizinga TW, Haney DJ, Shen Y, et al. Validation of a novel multibiomarker test to assess rheumatoid arthritis disease activity. Arthritis Care Res 2012;64:1794-803.

33. Bakker MF, Cavet G, Jacobs JW, Bijlsma JW, Haney DJ, Shen Y, et al. Performance of a multi-biomarker score measuring rheumatoid arthritis disease activity in the CAMERA tight control study. Ann Rheum Dis 2012;71:1692-7.

34. Vazquez I, Graell E, Gratacós J, Cañete JD, Viñas O, Ercilla MG, et al. Prognostic markers of clinical remission in early rheumatoid arthritis after two years of DMARDs in a clinical setting. Clin Exp Rheumatol 2007;25:231-8.

35. Gossec L, Dougados M, Goupille P, Cantagrel A, Sibilia J, Meyer $\mathrm{O}$, et al. Prognostic factors for remission in early rheumatoid arthritis: a multiparameter prospective study. Ann Rheum Dis 2004;63:675-80.

36. Jeanrenaud B, Rohner-Jeanrenaud F. Effects of neuropeptides and leptin on nutrient partitioning: dysregulations in obesity. Annu Rev Med 2001;52:339-51.

37. Lago R, Gomez R, Lago F, Gomez-Reino J, Gualillo O. Leptin beyond body weight regulation-current concepts concerning its role in immune function and inflammation. Cell Immunol 2008;252:139-45

38. Kopec-Medrek M, Kotulska A, Widuchowska M, Adamczak M, Wiecek A, Kucharz EJ. Plasma leptin and neuropeptide Y concentrations in patients with rheumatoid arthritis treated with infliximab, a TNF- $\alpha$ antagonist. Rheumatol Int 2012;32:3383-9.

39. Najafizadeh SR, Farahmand G, Roudsari AT, Heidari B, Larry M, Nargesi AA, et al. Absence of a positive correlation between CRP and leptin in rheumatoid arthritis. Heliyon 2016;2:e00205.

40. Xanthoulea S, Pasparakis M, Kousteni S, Brakebusch C, Wallach D, Bauer J, et al. Tumor necrosis factor (TNF) receptor shedding controls thresholds of innate immune activation that balance opposing TNF functions in infectious and inflammatory diseases. J Exp Med 2004;200:367-76.

41. Majumdar S, Aggarwal BB. Methotrexate suppresses NF-kappaB activation through inhibition of IkappaBalpha phosphorylation and degradation. J Immunol 2001;167:2911-20.

42. Becker C, Barbulescu K, Hildner K, Meyer zum Buschenfelde KH, Neurath MF. Activation and methotrexate-mediated suppression of the TNF alpha promoter in T cells and macrophages. Ann N Y Acad Sci 1998;859:311-4.

43. Hildner K, Finotto S, Becker C, Schlaak J, Schirmacher P, Galle PR, et al. Tumour necrosis factor (TNF) production by T cell receptor-primed $\mathrm{T}$ lymphocytes is a target for low dose methotrexate in rheumatoid arthritis. Clin Exp Immunol 1999;118:137-46.

44. Rudwaleit M, Yin Z, Siegert S, Grolms M, Radbruch A, Braun J, et al. Response to methotrexate in early rheumatoid arthritis is associated with a decrease of $\mathrm{T}$ cell derived tumour necrosis factor alpha, increase of interleukin 10, and predicted by the initial concentration of interleukin 4. Ann Rheum Dis 2000;59:311-4.

45. Dolhain RJ, Tak PP, Dijkmans BA, De Kuiper P, Breedveld FC, Miltenburg AM. Methotrexate reduces inflammatory cell numbers, expression of monokines and of adhesion molecules in synovial tissue of patients with rheumatoid arthritis. Br J Rheumatol 1998;37:502-8.

46. Kraan MC, Reece RJ, Barg EC, Smeets TJ, Farnell J, Rosenburg R, et al. Modulation of inflammation and metalloproteinase expression in synovial tissue by leflunomide and methotrexate in patients with active rheumatoid arthritis. Findings in a prospective, randomized, double-blind, parallel-design clinical trial in thirty-nine patients at two centers. Arthritis Rheum 2000;43:1820-30.

47. Klimiuk PA, Fiedorczyk M, Sierakowski S, Chwiecko J. Soluble cell adhesion molecules (sICAM-1, sVCAM-1, and sE-selectin) in patients with early rheumatoid arthritis. Scand J Rheumatol 2007;36:345-50.

Personal non-commercial use only. The Journal of Rheumatology Copyright @ 2019. All rights reserved. 